\title{
Effect of Glutamine on Apoptosis-inducing Factor Expression and Apoptosis of Glomerular Parietal Epithelial Cells of Cisplatin-exposed Rats
}

\author{
Ihsan Fahmi Rofananda ${ }^{1}$, Jusak Nugraha ${ }^{2}$, Imam Susilo $^{3 *}$, Miyayu Soneta Sofyan ${ }^{4}$ \\ ${ }^{1}$ Medicine Undergraduate Program, Faculty of Medicine, University of Airlangga, Surabaya, East Java, Indonesia; ${ }^{2}$ Department \\ of Clinical Pathology, Faculty of Medicine, University of Airlangga, Surabaya, East Java, Indonesia; ${ }^{3}$ Department of Anatomical \\ Pathology, Faculty of Medicine, University of Airlangga, Surabaya, East Java, Indonesia; ${ }^{4}$ Department of Health, Faculty of \\ Vocational Study, University of Airlangga, Surabaya, East Java, Indonesia
}

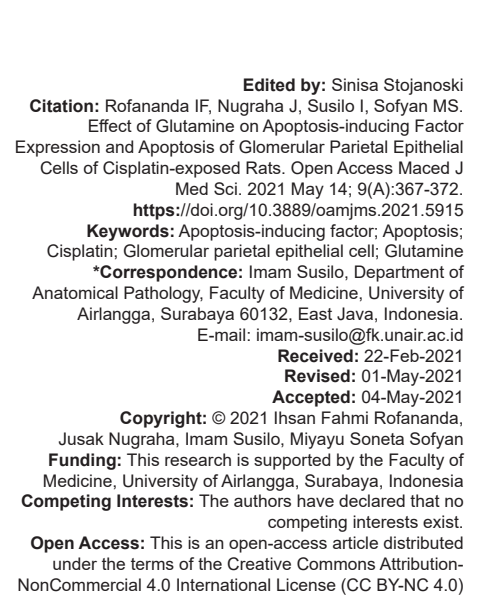

Abstract

AIM: This study analyzed the nephroprotective effect by examining apoptosis-inducing factor (AIF) expression and apoptosis rate in the glomerular parietal epithelial cell of cisplatin-exposed rats

METHODS: Samples consisted of 30 rats (divided into 3 groups: Group P0 received no treatment, group P1 received a cisplatin injection on the $7^{\text {th }}$ day, and group P2 received glutamine injection on days 1-7 and cisplatin injection on the $7^{\text {th }}$ day). After $72 \mathrm{~h}$, the tissue samples were immunohistochemically processed. AlF expression was measured in an Allred score. The apoptosis rate was measured in apoptotic cells/field of view. Statistical analysis was carried out using JASP Statistics ver. $0.12 .0(p<0.05)$

RESULTS: AIF expression values are follows: $\mathrm{P} 0=4.89 \pm 0.418, \mathrm{P} 1=6.14 \pm 0.685$, and $\mathrm{P} 2=4.95 \pm 0.530$. The Kruskal-Wallis test result showed a significant difference $(p<0.05)$ between the groups and Dunn's post hoc test showed a significant difference between $\mathrm{P} 0$ and $\mathrm{P} 1$ and between $\mathrm{P} 1$ and P2, but no significant difference between $\mathrm{P0}$ and P2. Meanwhile, apoptosis rate values are as follows: $\mathrm{P} 0=24.3 \pm 9.821, \mathrm{P} 1=123.6 \pm 16.008$, and $\mathrm{P} 2=77.2$ \pm 10.644 . The Kruskal-Wallis test result showed a significant difference $(p<0.05)$ between the groups, and Dunn's post hoc test showed a significant difference between $\mathrm{P} 0$ and $\mathrm{P} 1$, between $\mathrm{P} 1$ and $\mathrm{P} 2$, and between $\mathrm{P} 0$ and $\mathrm{P} 2$.

CONCLUSION: The expression of AIF and apoptosis of glomerular parietal epithelial cells of the cisplatin-exposed rat has decreased after glutamine treatment.

\section{Introduction}

Cancer is a term for a group of diseases that are characterized by rapid, abnormal cell growth beyond their usual boundaries and which can invade other body parts [1]. The prevalence of cancer in Indonesia has increased from $1-4 / 1000$ people in the population in 2013 to $1-79 / 1000$ people in the population in 2018 [2]. The increasing prevalence of cancer is affected by many factors such as population growth and changes in socioeconomic style in developing countries [1]. The increased incidence of cancer has led to an increase in the usage of chemotherapeutic drug, such as cisplatin. Cisplatin is one of the main chemotherapeutic drugs used in the treatment of many cancers such as bladder cancer, lung cancer, ovarian cancer, and testicular cancer. Cisplatin works by crosslinking purine bases of the DNA and inhibiting DNA repair, resulting in DNA damage and cell apoptosis [2]. Although it is extensively used in cancer treatment, cisplatin has a nephrotoxic side effect that could lead to acute kidney injury (AKI). Cisplatin's nephrotoxic effect is caused by apoptosis and necrosis of renal cells [3]. Cisplatin dose in cancer chemotherapy regime varies widely, from $25 \mathrm{mg} / \mathrm{m}^{2}$ in non-small cell lung cancer therapy to $100 \mathrm{mg} / \mathrm{m}^{2}$ in high-dose therapy regimen for head and neck cancer [4], [5]. Kidera et al. [6] found that $32 \%$ of patients undergoing high-dose cisplatin treatment $\left(\geq 60 \mathrm{mg} / \mathrm{m}^{2}\right.$ ) suffer from nephrotoxicity. AKI patients should undergo long-term dialysis and suffer from a decreasing quality of life. The mortality rate of hospitaltreated AKI patients ranged between $45 \%$ and $70 \%$ [7]. The most vulnerable part to nephrotoxic drugs is renal tubules because it plays a role in the reabsorption of filtrate containing toxins [8]. Besides renal tubules, the renal glomerulus can also be affected by the nephrotoxic effects of the drug. In experiments with guinea pigs, it was found that cisplatin caused damage to glomerular components: Glomerular capillaries, basement membranes, podocytes, mesangial cells, and parietal epithelial cells. The toxic effect of cisplatin is also observed in cytoplasmic organelles, such as mitochondria, nucleus, and endoplasmic reticulum [9]. The mechanism of nephrotoxicity in glomerular components can be through direct destruction of cells 
or drug-induced immunological mechanisms. However, there have not been many studies on nephrotoxicity in glomerular components [10].

Apoptosis is a programmed cell death in which a cell activates enzymes that digest DNA and cytoplasmic protein. There is an apoptotic pathway named the caspase-independent pathway, in which a key protein named apoptosis-inducing factor (AIF) plays a role. AIF is normally expressed in the mitochondria; however, in apoptosis, AIF will translocate to the cell nucleus and will induce chromatin condensation followed by DNA degradation [11]. Glutamine is an amino acid that is found abundantly in the human body [12], and it has the potential to inhibit apoptosis indirectly. Glutamine can induce the expression of $\mathrm{Hsp} 70$ by stimulating the hexosamine biosynthetic pathway [13]. Hsp70 can inhibit the translocation of AIF from the mitochondria, thus inhibiting the apoptosis process [14]. This study aims to analyze the nephroprotective effect of glutamine on the glomerular parietal epithelial cell by examining AIF expression and apoptosis rate in the glomerular parietal epithelial cell of cisplatin-exposed rats.

\section{Methods}

\section{Research design and samples}

This research is an experimental analytical study with samples of 30 healthy male rats (Rattus norvegicus Berkenhout, 1769, Wistar strain) aged 2-3 months, weighed 150-200 g, and obtained from Experimental Animal Unit, Faculty of Medicine, University of Airlangga, Indonesia. The sample size was obtained using the Federer formula $(n-1)(t-1)$ $\geq 15$, where $n$ is the sample size for each intervention and $t$ is the number of treatments [15]. The final sample size was adjusted for the expected death of $10 \%$ of the samples. Rats were housed with one-animal per cage with adequate air circulation and lighting. Rats had ad libitum water and pellet diet (Charoen Pokphand, Thailand). Rats were adapted to the laboratory conditions for 7 days before the experiment. All experiments in this study were approved by the Health Research Ethics Committee, Faculty of Medicine, University of Airlangga (ethical clearance no. 233/EC/KEPK/FKUA/2019).

\section{Cisplatin and glutamine treatment}

Rats were randomly divided into three groups of ten rats and treated as below:

P0: No treatment

Rats in the PO group were not given any treatment and served as controls.

$$
\text { - P1: Cisplatin }
$$

Rats in the P1 group received a single dose of intraperitoneal cisplatin (Kalbe Farma, Indonesia) injection at a dose of $20 \mathrm{mg} / \mathrm{kg} \mathrm{BW}$ on the 7th day, to induce nephrotoxicity.

\section{- $\quad$ P2: Glutamine + cisplatin}

Rats in the $\mathrm{P} 2$ group were given glutamine (Serva, Germany) on days 1-7. Approximately $1 \mathrm{~g}$ of glutamine was dissolved in $10-\mathrm{ml} \mathrm{NaCl} 0.9 \%$ (Braun, Malaysia) and administered intravenously into the tail vein, at a dose of $100 \mathrm{mg} / \mathrm{kg} \mathrm{BW}$, and each injection should be no more than $0.2 \mathrm{ml} /$ day. On the $7^{\text {th }}$ day, rats in the P2 group received the same cisplatin treatment as rats in the $\mathrm{P} 1$ group.

All rats were sacrificed in the $10^{\text {th }}$ day by cervical dislocation following anesthesia with ether, and their kidneys were removed. The 72-h time between cisplatin administration and rat sacrifice was needed because cisplatin-induced nephrotoxicity starts to show the effect in 3 days after cisplatin administration [16].

\section{AIF expression evaluation}

The kidneys were fixed in $10 \%$ formaldehyde (Polysciences, Taiwan) and embedded in paraffin (Slee, Germany). Kidney sections were cut by a microtome (Leica Biosystems, US) at $4 \mu \mathrm{m}$ thickness and were then mounted on object glasses (Sail Brand, China). Slides were deparaffinized and rehydrated using a gradual change of xylene (Merck, Germany) and ethanol (Merck, Germany). AIF expression was evaluated with immunohistochemistry using the streptavidin-peroxidase technique. Kidney specimens were incubated with $5 \%$ fetal bovine serum (Thermo Fisher Scientific, USA) containing $0.25 \%$ Triton X-100 (Thermo Fisher Scientific, USA). This was followed by incubation with $10 \mu \mathrm{g} / \mathrm{ml}$ primary antibody (anti-AIF antibody [Thermo Fisher Scientific, USA]) overnight at $40^{\circ} \mathrm{C}$. Specimens were then incubated with the biotin-conjugated anti-mouse antibody (Thermo Fisher Scientific, USA) for $1 \mathrm{~h}$ at $25^{\circ} \mathrm{C}$ and followed by incubation with HRP-conjugated streptavidin (Thermo Fisher Scientific, USA) for $40 \mathrm{~min}$. Antibody binding was visualized by staining with diaminobenzidine (Merck, Germany), followed by counterstaining with Mayer's hematoxylin (Polysciences, Taiwan). Kidney specimens were observed under a light microscope (400x magnification) (BX53, Olympus, Japan) in ten fields of view: Three in the kidney's upper pole, four in the middle pole, and three in the lower pole. Immunoreactive cells stained brown, while non-immunoreactive cells stained blue. AIF expression is stated in the Allred score.

\section{Apoptosis detection}

The kidneys were fixed in $10 \%$ formaldehyde (Polysciences, Taiwan) and embedded in paraffin (Slee, 
Germany). Kidney sections were cut by a microtome (Leica Biosystems, US) at 4- $\mu \mathrm{m}$ thickness and were then mounted on object glasses (Sail Brand, China).After deparaffinization and rehydration using a gradual change of xylene (Merck, Germany) and ethanol (Merck, Germany), apoptosis was studied with terminal deoxynucleotidyl transferase 2'-deoxyuridine 5'triphosphate (dUTP) nick end labeling (TUNEL) assay using in situ Cell Death Detection Kit, POD (Roche, Germany). Briefly, specimens were treated with proteinase $\mathrm{K}$ (Bioline, London) for $15 \mathrm{~min}$. Endogenous peroxide was blocked by adding $3 \% \mathrm{H}_{2} \mathrm{O}_{2}$ (Boster, USA) and incubated for $5 \mathrm{~min}$ at $25^{\circ} \mathrm{C}$ and was followed by incubation in working strength terminal deoxynucleotidyl transferase enzyme (Roche, USA) in the tissue and then incubated at $37^{\circ} \mathrm{C}$ in a humid container for $1 \mathrm{~h}$. Thereafter, the specimens were incubated in peroxidase-conjugated anti-digoxigenin antibody (Biocompare, USA) in a humid container for $30 \mathrm{~min}$. Staining was performed by incubation with peroxidase substrate (Thermo Fisher Scientific, USA) and subsequently followed by counterstaining with methyl green (Merck, Germany). Kidney specimens were observed under a light microscope (400× magnification) (BX53, Olympus, Japan) in ten fields of view: Three in the kidney's upper pole, four in the middle pole, and three in the lower pole. Apoptotic nuclei stained brown, while nonapoptotic nuclei stained green. The apoptosis rate was stated in the number of apoptotic cells/field of view.

\section{Statistical analysis}

Statistical analysis was carried using JASP Statistics ver. 0.12 .0 (University of Amsterdam). AIF expression data and apoptosis data were tested for distribution normality using the Shapiro-Wilk test and also tested for homogeneity using the Levene test. If the data were distributed normally and homogenous, the Analysis of Variance (ANOVA) test was commenced to see if there were any differences between the groups, and if any, least significant difference test would be commenced. If the data were not distributed normally and/or not homogenous, the Kruskal-Wallis test would be commenced to see if there were any differences between the groups, and if any, Dunn's post hoc test would be commenced. Statistical significance was defined as $p<0.05$.

\section{Results}

\section{Morphology of glomerular parietal epithelium}

There are four types of glomerular cells, namely, podocytes, mesangial cells, endothelial cells, and parietal epithelial cells. Parietal epithelial cells are flat (about 0.2- $\mu \mathrm{m}$ thick), but their thickness increases at the nucleus. These cells are inconspicuous under the light microscope. At the glomerular vascular pole, parietal epithelial cells form a junction with podocytes. Meanwhile, in the urinary pole, parietal epithelial cells form a junction with proximal tubular cells (Figure 1).

\section{Glutamine treatment reduces AIF expression}

AIF expression is measured using the Allred score, which measures the number of cells expressing AIF and intensity of expression. The Kruskal-Wallis $p$-value is $0.0141(\alpha=0.05)$; thus, there is a significant difference $(p<0.05)$ between the groups. Following cisplatin exposure, AIF expression rises significantly (Dunn's post hoc test, $\mathrm{p}<0.05$ ) in rats in the $\mathrm{P} 1$ group; however, in rats in the P2 group, which was pretreated with glutamine, the AIF expression does not differ significantly (Dunn's post hoc test, $p>0.05$ ) with rats in the control group (P0) (Tables 1 and 2).

Table 1: Apoptosis-inducing factor expression score in P0, P1, and $\mathrm{P} 2$ animals

\begin{tabular}{ll}
\hline Group & Apoptosis-inducing factor expression score \\
\hline P0 & $4.89 \pm 0.417532434$ \\
P1 & $6.14 \pm 0.685079071$ \\
P2 & $4.95 \pm 0.529674953$ \\
\hline
\end{tabular}

Table 2: Dunn's post-hoc test result for apoptosis-inducing factor expression

\begin{tabular}{llll}
\hline Comparison & Average difference & $p$ value $(\alpha=0.05)$ & Interpretation \\
\hline P0-P1 & -3.489 & 0.029 & Different \\
P0-P2 & 0.013 & 0.495 & Not different \\
P1-P2 & 3.502 & 0.035 & Different \\
\hline
\end{tabular}

\section{Glutamine treatment reduced apoptosis}

rate

The apoptosis rate is measured by counting the number of apoptotic cells in ten fields of view per kidney

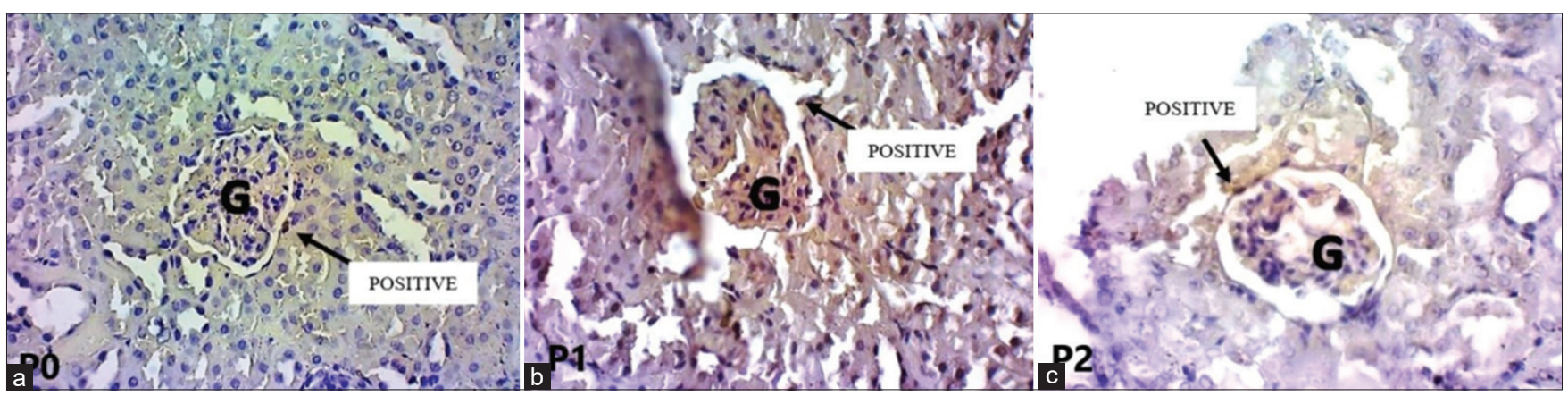

Figure 1: (a-c) Morphology of glomerulus. "G" shows the glomerulus, Arrow mark shows the apoptosis-inducing factor-immunoreactive ("positive") glomerular parietal epithelial cell 
specimen. The Kruskal-Wallis $p=0.0044(\alpha=0.05)$; thus, there is a significant difference $(p<0.05)$ between the groups. Following cisplatin exposure, the number of apoptotic cells rose significantly (Dunn's post hoc test, $p<0.05$ ) in rats in the P1 group. The apoptotic cell number in rats in the P2 group, which was pretreated with glutamine, also increases significantly (Dunn's post hoc test, $p<0.05$ ) compared to rats in the control group (P0), but it is significantly lower than rats in the P1 group (Dunn's post hoc test, $\mathrm{p}<0.05$ ) (Tables 3 and 4).

Table 3: Apoptosis rate in P0, P1, and P2 animals

\begin{tabular}{ll}
\hline Group & Average number of apoptotic cell \\
\hline P0 & $24.3 \pm 9.821178929$ \\
P1 & $123.6 \pm 16.00833116$ \\
P2 & $77.2 \pm 10.64372533$ \\
\hline
\end{tabular}

Table 4: Dunn's post-hoc test result for apoptosis rate

\begin{tabular}{llll}
\hline Comparison & Average difference & $\mathrm{p}$ value $(\alpha=0.05)$ & Interpretation \\
\hline P0 - P1 & -5.082 & 0.012 & Different \\
P0 - P2 & -2.541 & 0.006 & Different \\
P1 - P2 & 2.541 & 0.006 & Different \\
\hline
\end{tabular}

\section{Correlation between AIF expression and apoptosis rate}

Spearman's rank correlation test was performed to find whether AIF expression and apoptosis rate correlate or not. The correlation between AIF expression and apoptosis rate results in the $p=$ $0.000083(\alpha=0.05)$. These results indicate that there is a correlation where the magnitude of the correlation coefficient $(R)$ is 0.642 , which means it is moderately related and in positive correlation (Table 5).

Table 5: Spearman's rank correlation test

\begin{tabular}{lll}
\hline & Spearman's rho & $\mathrm{p}$ \\
\hline Apoptosis & 0.642 & 0.000083 \\
\hline All tests one-tailed, for positive correlation. &
\end{tabular}

All tests one-tailed, for positive correlation.

\section{Discussion}

This research aims to analyze the nephroprotective effect of glutamine on AIF expression in the apoptosis of glomerular parietal epithelial cells of cisplatin-exposed rats. The rats used in this research were divided into three groups, the $\mathrm{P0}$ group as the control group, the P1 group as the group administered with cisplatin to induce nephrotoxicity, and the group P2 as the group administered with glutamine before cisplatin administration. After 3 days, the rats were sacrificed, and kidney tissues were processed with immunohistochemistry stain to detect AIF expression. The kidney tissues were also processed with in situ Cell Death Detection Kit to detect apoptosis.

Our findings show that glomerular parietal epithelial cells were affected by Cisplatin's nephrotoxic properties, resulting in higher AIF expression and apoptosis rate. The result of this research is in accordance with previous studies, which showed that cisplatin in high dose $\left(\geq 60 \mathrm{mg} / \mathrm{m}^{2}\right)$ could induce cisplatininduced nephrotoxicity [3], [6]. Cisplatin dose in cancer chemotherapy regime varies widely, from $25 \mathrm{mg} / \mathrm{m}^{2}$ in non-small cell lung cancer therapy to $100 \mathrm{mg} / \mathrm{m}^{2}$ in highdose therapy regimen for head and neck cancer [4], [5]. In cisplatin administration during the cancer treatment, the kidney accumulates cisplatin, and this accumulation is exacerbating the nephrotoxic effect of cisplatin [2]. Some preexisting conditions are more prone to cisplatininduced nephrotoxicities such as high cisplatin dose, higher frequency of cisplatin regimen, higher cumulative dose, concomitant use of other nephrotoxic drugs, female sex, older age, smoking, hypoalbuminemia, history of cisplatin use, and hydration without magnesium [17], [18]. Although cisplatin treatment mainly affects the tubulointerstitial part of the kidney [10], glomerular components, such as capillary endothelium, basement membrane, podocyte, mesangial cell, and the parietal cell, can also be damaged by cisplatin administration [9]. Cisplatin can induce the activation of p53, which will result in increased expression of Puma and Noxa, which are members of the $\mathrm{BH} 3$-only protein proapoptotic family. Puma and Noxa will encourage the activation of Bax and Bak so that mitochondrial outer membrane permeabilization (MOMP) occurs and AIF will translocate into the nucleus. In addition to activating Puma and Noxa, p53 also encourages PIDD expression, where PIDD will encourage caspase-2 activation so that MOMP occurs [19]. In their research, Liu et al. [20] found that cisplatin caused the activation of $\mu$-calpain, a protein that can help release AIF from the mitochondria, causing apoptosis. In our findings, although there is no significant difference between the expression of AIF in the P0 and P2 groups, the level of apoptosis is significantly higher in the P2 group compared with the $\mathrm{PO}$ group. We suspect that this phenomenon is related to the fact that cisplatin also causes the activation of apoptotic pathways that do not require AIF. Therefore, the apoptosis rate is still increased in the P2 group even though apoptosis levels were significantly reduced than the P1 group, which only received cisplatin injection without getting glutamine injection.

This research also shows that glutamine administration could inhibit cisplatin-induced nephrotoxicity, resulting in lower AIF expression and lower apoptosis rate. This is in accordance to the results of previous research, showing that glutamine can induce Hsp70 production, which can inhibit the translocation of AIF into the cell nucleus [13], [14]. Hsp70 is a protein that functions in protein folding, ranging from folding and preparing new proteins, refolding defective proteins, translocating membranes from organelle and secretory proteins, and controlling the activity of regulatory proteins. $\mathrm{Hsp} 70$ activation is related to the stress response, where stress conditions can increase Hsp70 levels. Hsp70 interacts with proteins that act as key regulators in the 
signal transduction pathway controlling proliferation, differentiation, and apoptosis [21]. Matsumori et al. [22] found that there was an interaction between Hsp70 and AIF on the result of immunoprecipitation. The amount of interaction between the two is inversely proportional to the number of AIF translocations to the cell nucleus, but not the AIF translocations to the cytosol. These results indicate that the interaction of $\mathrm{Hsp} 70$ and AIF might decrease the downstream reaction of the apoptotic pathway, one of which is the translocation of AIF to the nucleus. In addition to inducing Hsp70 expression, administration of glutamine can also reduce the uptake of glutamine by renal tubular cells, thereby reducing cisplatin accumulation in the kidney, so that the effect of cisplatin nephrotoxicity is also reduced [23].

Previous studies have shown that many types of cancer cells show increased glutamine consumption and dysregulation of glutamine-processing enzymes such as glutaminases and glutamine synthase, suggesting that targeting glutamine metabolism shows promise as an anticancer therapy [24], [25]. However, in their research using in vitro cell culture, Kim et al. [23] suggest that the protective effect of glutamine on cell viability is specific to renal cells, compared with tumor cells. This suggests that glutamine may be used in cancer therapy to counter the nephrotoxic effect of cisplatin. However, further research must be conducted to find out whether glutamine decreases Cisplatin's tumoricidal properties or not.

There are limitations in this study that should be noted. In this study, we use small sample size, which limits the generalizability of the findings and introduces uncertainty regarding the statistical power. In addition, we did not use cancer-induced animals; thus, we cannot evaluate the distortion of Cisplatin's tumoricidal effect in the presence of glutamine treatment. Furthermore, due to the nature of animal model research, our study is not free from bias resulting from physiological and immunological alterations due to stressful environment and laboratory procedures [26].

Further studies are necessary to investigate the effect of glutamine on glomerular cell death through different pathways. Elucidation of such pathways may lead to a better understanding of the glomerular damage observed in cisplatin treatment. In addition, further studies are needed to study the tumoricidal effect of cisplatin in the presence of glutamine treatment. Therefore, the use of glutamine as a nephroprotective material can be considered for future cancer treatment to prevent the nephrotoxic effects of cisplatin.

\section{Conclusion}

Intravenous glutamine injection could
significantly decrease both AIF expression and

apoptosis in glomerular parietal epithelial cells in the cisplatin-exposed rat. From this result, it can be assumed that glutamine has a nephroprotective effect against cisplatin-induced nephrotoxicity.

\section{Acknowledgment}

The authors would like to thank all parties which cannot be mentioned individually - who have participated in the making of this article.

\section{References}

1. Bray F, Ferlay J, Soerjomataram I, Siegel RL, Torre LA, Jemal A. Global cancer statistics 2018: GLOBOCAN estimates of incidence and mortality worldwide for 36 cancers in 185 countries. CA Cancer J Clin. 2018;68(6):394-424. https://doi. org/10.3322/caac.21492

PMid:30207593

2. Dasari S, Tchounwou PB. Cisplatin in cancer therapy: Molecular mechanisms of action. Eur J Pharmacol. 2014;1:364-78. PMid:25058905

3. Pabla N, Dong Z. Cisplatin nephrotoxicity: Mechanisms and renoprotective strategies. Kidney Int. 2008;73(9):994-1007. https://doi.org/10.1038/sj.ki.5002786 PMid:18272962

4. Aljubran A, Leighl N, Pintilie M, Burkes R. Improved compliance with adjuvant vinorelbine and cisplatin in non-small cell lung cancer. Hematol Oncol Stem Cell Ther. 2009;2(1):265-71. https://doi.org/10.1016/s1658-3876(09)50036-2 PMid:20063556

5. Szturz P, Wouters K, Kiyota N, Tahara M, Prabhash K, Noronha V, et al. Low-dose vs. high-dose cisplatin: Lessons learned from 59 chemoradiotherapy trials in head and neck cancer. Front Oncol. 2019;9:86. https://doi.org/10.3389/fonc.2019.00086 PMid:30874300

6. Kidera Y, Kawakami H, Sakiyama T, Okamoto K, Tanaka K, Takeda M, et al. Risk factors for cisplatin-induced nephrotoxicity and potential of magnesium supplementation for renal protection. PLoS One. 2014;9(7):e101902. https://doi.org/10.1371/journal. pone.0101902

PMid:25020203

7. Wald R, Quinn RR, Luo J, Li P, Scales DC, Mamdani MM, et al Chronic dialysis and death among survivors of acute kidney injury requiring dialysis. JAMA. 2009;302(11):1179-85. https:// doi.org/10.1001/jama.2009.1322

PMid:19755696

8. Perazella MA. Pharmacology behind common drug nephrotoxicities. Clin J Am Soc Nephrol. 2018;13(12):1897-908. PMid:29622670

9. Kohn S, Fradis M, Ben-David J, Zidan J, Robinson E. Nephrotoxicity of combined treatment with cisplatin and gentamicin in the guinea pig: Glomerular injury findings. Ultrastruct Pathol. 2002;26(6):371-82. https://doi. org/10.1080/01913120290104683

PMid: 12537762 
10. RadhakrishnanJ,PerazellaMA.Drug-inducedglomerulardisease: Attention required! Clin J Am Soc Nephrol. 2015;10(7):1287-90. PMid:25876771

11. Bröker LE, Kruyt FA, Giaccone G. Cell death independent of caspases: A review. Clin Cancer Res. 2005;11(9):3155-62. https://doi.org/10.1158/1078-0432.ccr-04-2223

PMid:15867207

12. Matés JM, Segura JA, Alonso FJ, Márquez J. Pathways from glutamine to apoptosis. Front Biosci. 2006;11:3164-80. PMid:16720383

13. Hamiel CR, Pinto S, Hau A, Wischmeyer PE. Glutamine enhances heat shock protein 70 expression via increased hexosamine biosynthetic pathway activity. Am J Physiol Cell Physiol. 2009;297(6):C1509-19. https://doi.org/10.1152/ ajpcell.00240.2009 PMid:19776393

14. Kim JY, Han Y, Lee JE, Yenari MA. The 70-kDa heat shock protein (Hsp70) as a therapeutic target for stroke. Expert Opin Ther Targets. 2018;22(3):191-9. https://doi.org/10.1080/147282 22.2018.1439477

\section{PMid:29421932}

15. Federer WT. Experimental Design: Theory and Application. Calcutta: Oxford \& IBH; 1967.

16. Tsuruya K, Ninomiya T, Tokumoto M, Hirakawa M, Masutani K, Taniguchi $\mathrm{M}$, et al. Direct involvement of the receptormediated apoptotic pathways in cisplatin-induced renal tubular cell death. Kidney Int. 2003;63(1):72-82. https://doi. org/10.1046/j.1523-1755.2003.00709.x PMid:12472770

17. Miller RP, Tadagavadi RK, Ramesh G, Reeves WB. Mechanisms of cisplatin nephrotoxicity. Toxins (Basel). 2010;2(11):2490-518. https://doi.org/10.3390/toxins2112490

\section{PMid:22069563}

18. Yamamoto $\mathrm{Y}$, Watanabe K, Matsushita H, Tsukiyama I, Matsuura K, Wakatsuki A. Multivariate analysis of risk factors for cisplatin-induced nephrotoxicity in gynecological cancer. J Obstet Gynaecol Res. 2017;43(12):1880-6. https://doi. org/10.1111/jog.13457
PMid:28984058

19. Kroemer G, Martin SJ. Caspase-independent cell death. Nat Med. 2005;11(7):725-30

PMid:16015365

20. Liu L, Xing D, Chen WR. Micro-calpain regulates caspasedependent and apoptosis inducing factor-mediated caspaseindependent apoptotic pathways in cisplatin-induced apoptosis. Int J Cancer. 2009;125(12):2757-66. https://doi.org/10.1002/ ijc. 24626 PMid:19705411

21. Mayer MP, Bukau B. Hsp70 chaperones: Cellular functions and molecular mechanism. Cell Mol Life Sci. 2005;62:670-84. https://doi.org/10.1007/s00018-004-4464-6

PMid:15770419

22. Matsumori $\mathrm{Y}$, Hong SM, Aoyama $\mathrm{K}$, Fan $\mathrm{Y}$, Kayama $\mathrm{T}$ Sheldon RA, et al. Hsp70 overexpression sequesters AIF and reduces neonatal hypoxic/ischemic brain injury. J Cereb Blood Flow Metab. 2005;25(7):899-910. https://doi.org/10.1038/ sj.jcbfm. 9600080

PMid:15744251

23. Kim HJ, Park DJ, Kim JH, Jeong EY, Jung MH, Kim TH, et al. Glutamine protects against cisplatin-induced nephrotoxicity by decreasing cisplatin accumulation. J Pharmacol Sci. 2015;127(1):117-26. https://doi.org/10.1016/j.jphs.2014.11.009 PMid:25704027

24. Altman BJ, Stine ZE, Dang CV. From Krebs to clinic: Glutamine metabolism to cancer therapy. Nat Rev Cancer. 2016;16(10):619-34. https://doi.org/10.1038/nrc.2016.71 PMid:27492215

25. Matés JM, Campos-Sandoval JA, de los Santos-Jiménez JL, Márquez J. Dysregulation of glutaminase and glutamine synthetase in cancer. Cancer Lett. 2019;467:29-39. https://doi. org/10.1016/j.canlet.2019.09.011

PMid:31574293

26. Balcombe JP, Barnard ND, Sandusky C. Laboratory routines cause animal stress. Contemp Top Lab Anim Sci. 2004;43(6):42-51.

PMid:15669134 